\title{
LLANO ZAPATA, UN CRIOLLO APOLOGISTA DE ESPAÑA Intercambio apologético-critico sobre la colonización española a mediados del siglo XVIII
}

\author{
ANTONIO MeStRE SANCHIS
}

Fecha de recepción: noviembre 2011

Fecha de aceptación: febrero 2012

En el inmenso piélago epistolar de Gregorio Mayans hay correspondencia con personajes que se presentan de múltiples formas y contenidos. Las hay familiares (padres, hermanos, esposa e hijos), si bien en algún caso con los hermanos Manuel y Juan Antonio, que aportan interesantes noticias culturales. Pero la mayor parte de las cartas tienen un evidente contenido erudito. Hay correspondencias continuadas que expresan la evolución cultural de personas e instituciones, tanto entre españoles (Bordazar, Burriel, Martínez Pingarrón...) como extranjeros (Gerardo Meerman). Asimismo encontramos correspondencia con personajes de reconocido prestigio acerca de temas concretos, como Muratori en el campo de la epigrafía y del catolicismo ilustrado, Antonio Pereira en el mundo cultural hispano-luso en tiempo de Pombal o del embajador británico Benjamín Keene sobre los orígenes del cervantismo en España.

Sin embargo, entre tantos millares de cartas hay hallazgos sorprendentes. Son como destellos luminosos de un tema apenas esbozado que desaparecen fugazmente y dejan un sabor agridulce, con el deseo de un desarrollo que no llega. El ejemplo más clamoroso es el breve cruce de cartas del erudito con Voltaire, centrado en las conexiones del teatro francés del siglo XVII con los grandes autores hispanos del Barroco.

Ahora bien, si en este caso la importancia radica en el significado simbólico del philosophe por excelencia, hay otro ejemplo de correspondencia -breve pero intensaque aborda un tema de enorme trascendencia: la colonización española de América. El corresponsal de don Gregorio fue el peruano José Eusebio Llano Zapata, autor de unas Memorias histórico-physico críticas de la América Meri-Dional, obra proyectada en 4 volúmenes y cuyo primer tomo apareció en 1758. La correspondencia fue escasa, 2 cartas de Llano Zapata a Mayans y 2 cartas del erudito en respuesta a las inquietudes del historiador peruano. En Apología y crítica de España en el siglo XVIII (2003), insi- 
nué la existencia de esta correspondencia, pero ahora creo interesante hacer un estudio más minucioso de las razones en que basaban su discurso.

\section{EL CAMPO DE LA CORRESPONDENCIA}

Evidentemente Mayans no fue un historiador centrado en temas americanos. Pero, dada su insaciable curiosidad intelectual, abordó circunstancialmente aspectos relativos a las provincias hispanas de América. Además, conquista y colonización españolas -temas históricos trascendentes- habían sido objeto de su interés. La presencia en Perú de un discípulo suyo Juan José Amusquibar que, como favorecido del inquisidor general Andrés Orbe, había sido nombrado inquisidor en Lima, le proporcionaba alguna noticia de América del Sur. Ahora bien, había tres factores que, en 1757-1758, años de la correspondencia con Llano Zapata, le habían proporcionado interesantes noticias. Aludiré con brevedad a ellos, sin seguir rigurosamente el orden cronológico.

Durante los años como bibliotecario real en Madrid, mantuvo muy buenas relaciones con el Consejero de Castilla González de Barcia. Pues bien, el Consejero había publicado una serie de obras relativas a la colonización y a la historiografía americanas. Había impreso la Monarchía Indiana con el origen, guerras de los indios occidentales, de sus poblaciones, descubrimientos, conquista, conversión... de Fr. Juan de Torquemada en 1723. Ese mismo año González de Barcia publicó La Florida del Inca... por Garcilaso de la Vega (el Inca). Y en 1737-1738 dio a la prensa el Epítome de la Bibliotheca oriental i occidental... de Antonio León Pinelo. Eran libros bien conocidos por Mayans que cita con frecuencia, especialmente a León Pinelo. Por lo demás, unas advertencias del P. Torquemada acerca la paternidad del jesuita José de Acosta sobre la Historia natural y moral de las Indias, provocó un minucioso análisis por parte de Llano Zapata.

Un segundo factor a considerar es la interesante relación del erudito con el italiano Lorenzo Boturini que, después de residir unos años en Méjico, fue desterrado a España por el virrey duque de Fuenclara. Pues bien, Boturini había recogido numerosos restos arqueológicos anteriores a los descubrimientos colombinos. Sólo pudo editar en España Idea de una nueva Historia General de la América Septentrional (Madrid, 1746), pero la sospecha de que defendía las teorías de Juan Bautista Vico le creó muchos enemigos en la Corte. De hecho, Boturni estuvo en la casa solariega de Mayans, formó parte de la Academia Valenciana (creada por el erudito) donde pronunció una Oratio sobre el derecho natural (1750). Esta amistad permitió a don Gregorio conocer el valor de los restos arqueológicos precolombinos (figuras, símbolos, caracteres, jeroglíficos...) y lamentar públicamente la actitud de los conquistadores que, sin conocer su sentido y alcance, los destruyeron. He aquí las palabras sobre la Historia cronológica de la América Septentrional de Boturini, en carta al duque de Sotomayor, que repetirá Llano Zapata en su carta al erudito. «Les faltaba (a los indios) el conocimiento de la lengua, que es el principal instrumento de la sociedad humana, y medio único de aprehender, no haviendo libros. Los indios suplían la falta de éstos con pinturas, natural y antiguo medio de historiar las cosas, pero dificultoso e impenetrable sin peritíssimos maestros. 
Los españoles, que veían aquellas pinturas, imaginando ver representaciones de ídolos, las quemaron, rasgaban, enterraban o corrompían, de que hay muchos exemplos en la Historia Indiana. De donde nació un daño irreparable en lo tocante a la memoria de las cosas passadas» (Cartas morales, II, pp. 664-665.).

Este es un factor que llamó la atención de Llano Zapata. Porque, después de confesar que leyó con gusto las epístolas latinas de Mayans y los archivos, «igualmente he estudiado (tal qual he podido) los Quipos o Annales que aun, a pesar del desprecio y la ignorancia, hasta hoy se encuentran algunas reliquias de ellos en templos arruinados, palacios destruidos y otros monumentos de la antigüedad. Los que verdaderamente, si se huvieran tenido como el más precioso tesoro de nuestras Indias, servirían a la historia de aquella luz, que apenas hoy podemos encontrar en tan grande obscuridad y confusión de noticias, si queremos averiguar los orígenes de aquella vasta monarchía». Y no deja de comparar esos quipos con los restos, símbolos y hierogríficos hallados por Boturini en Méjico.

El tercer factor es la amistad del erudito con el peruano José Pardo de Figueroa, noble peruano a quien don Gregorio conoció personalmente en Madrid y que aparece vinculado directamente con esta historia. Mayans viajó a la Corte en 1727, acompañando a su padre para cobrar del conde de Oropesa el capital prestado al aristócrata durante el asedio de Barcelona por parte de las tropas borbónicas. La ocasión parecía propicia después del Tratado de Viena (1725) y el regreso de los austracistas exiliados. Pero, si bien el intento de recuperar el dinero prestado constituyó un fracaso (el padre del erudito tuvo que esperar unos cuantos años para cobrar), las relaciones culturales, establecidas por el joven catedrático con los hombres de letras residentes en la Corte, fueron intensas. He aquí sus palabras: «He registrado todas las librerías públicas y también he visto las de algunos Consejeros, las de los señores Barcia, Pardo, Fajardo, marqués de Villena y la Real. He quedado pasmado. Todo se pasa en visitar a estos señores que me hacen más merced de la que yo merezco. D. Álvaro de Castilla me favoreció muchísimo. Bustamante es bellísimo. Hoy estoy aplazado para volver a ver la librería de D. Gerónimo Pardo, que quiere que registre de espacio su mucha erudición. El marqués de Villena también me dijo ayer que desea vaya toda una tarde. D. José Bermúdez me favorece muchísimo» ${ }^{1}$.

Esas relaciones permitieron aumentar las conexiones político-culturales del erudito; $y$, como consecuencia del favor del abogado José Bermúdez, inició correspondencia con el peruano José Pardo de Figueroa, residente durante unos años en Madrid. En 1729 Mayans envió a Pardo de Figueroa la Oración sobre la Inmaculada Concepción, y pronto intercambiaron cartas, libros, criterios y bastantes chismes sobre la actitud de Mañer, en que se vieron involucrados Feijoo, Juan Iriarte y el mismo Mayans, que el erudito cuenta en diversas ocasiones. Pardo de Figueroa aconsejó, además, al erudito

\footnotetext{
1. G. Mayans a J. B. Cabrera, 17-X-1727, Texto en A. Mestre SAnChIS, Don Gregorio Mayans entre la erudición y la cultura, Valencia, 1999, p. 58.
} 
que buscase el favor y protección del marques de la Compuesta, Secretario de Estado de Gracia y Justicia.

Pero centrando la atención en el tema que nos ocupa, Pardo de Figueroa envió al erudito de Oliva a lo largo de 1731 Praedium rusticum, poema latino del francés Jacobo Vaniere, lo que propició que hablaran de los productos americanos como el cacao y la chirimoya. El peruano envió simientes de chirimoya para que las sembrasen en Oliva. Y, como en ese momento, Mayans preparaba la edición de Epistolarum libri sex (1732), incluyó una carta latina con la respuesta de Pardo de Figueroa sobre estos frutos de la agricultura americana. Más aún, el erudito trató al peruano durante los años de residencia en Madrid como bibliotecario real.

Pardo de Figueroa marchó a Lima en 1735 y, aunque por testimonio de Juan Antonio hubo quejas por parte de los Mayans: «Dios quiera que (Amusquíbar) cumpla lo que ofrece de desencarcelar alguna obra de Apolo (Mayans). Con Arenaza podrá remitir algo, si no se olvida como Pardo de la oferta» ${ }^{2}$, el aristócrata peruano siempre habló bien, tanto de la erudición como de la persona de don Gregorio. Tenemos en este sentido las palabras del inquisidor Amusquibar y, sobre todo, de Llano Zapata. Así lo demuestran las palabras del historiador peruano al presentarse. Después de confesar su admiración por el erudito de Oliva, escribe. «Casualmente tuve noticia de Vmd. Leía yo en mi patria por entretenimiento las Epístolas Familiares de Cicerón. Entró de visita a casa de mi padre, D. Joseph Augustín Pardo de Figueroa, marqués de Valle Umbroso, correspondiente y amigo de Vmd. Hallóme ocupado en aquella lección. Pareciéndole a este literato que no aprovecharía menos en aquel príncipe de la eloquencia romana que aprehendería de Vmd., su grande imitador, me dio a leer una colección de Cartas latinas, que havía Vmd., vol. en 4 impresso en Madrid³ . Leí este libro muchas veces instruyéndome cada día más y más con su manexo. Puedo asegurar a Vmd. que, quando no se encontrara en él otra cosa que el prólogo, debe passar por cabeza de obra en su género, si guardan las reglas que él prescribe».

Nacido en Lima, y educado en el colegio de la Compañía, poseía una buena formación humanista. En 1757 se encontraba en España y se disponía, con la protección expresa del bailío Julián de Arriaga, Secretario de Estado de Indias, a publicar unas Memorias histórico-physica-críticas de la América Meri-Dional. De cualquier forma, Llano Zapata era conocido en Cádiz, donde vivía. Porque todo el mundo de la cultura sabía que estaba escribiendo, por orden o al menos con el apoyo del Secretario de Estado de Indias, unas Memorias histórico-physico-críticas de la América MeriDional. Así se demuestra porque el mismo Llano Zapata solicitó del Dr. Francisco

2. Andrés I. Orbe a J. A. Mayans, 30-XII-1744, en G. MAYANS Y SISCAR, Epistolario XX. Los hermanos Mayans y los inquisidores, 1. La «clientela» del inquisidor Andrés Orbe, Estudio preliminar, transcripción y notas de A. Alemany Peiró, Valencia, Ayuntamiento de Oliva, 2005.

3. Aunque la cita es confusa, la indicación del prólogo demuestra que se trata de Epistolarum libri sex de Mayans, editado en Valencia, en 1732. En consecuencia, queda descartada la posibilidad de que aludiera a Epistolarum libri duodecim de Manuel Martí (que el mismo Mayans había preparado) y había aparecido en Madrid en 1735. 
Pujol unas noticias sobre las teorías acerca los cordiales y las fiebres. Pues bien, el Dr. Pujol escribe en su respuesta: sabe que Llano está «tan ocupado en el serio asumpto de escribir de orden de nuestro tan zeloso y juicioso Ministro, una tan dilatada, útil y trabajosa obra como es: Memorias histórico-physico...». Y, por supuesto, alaba que, entre tanto esfuerzo historiográfico, encuentre tiempo para preocuparse de asuntos médicos ${ }^{4}$

Y desde Cádiz escribió el 28 de noviembre de 1757 a su admirado Gregorio Mayans con el deseo de servirle y, después de comunicarle que citaba al erudito «tratando de la chirimoya», elogiosamente por supuesto. Por lo demás, Llano Zapata incluía dos cartas suyas impresas sobre el tema.

Según costumbre, Mayans contestó con amabilidad el 24 de diciembre del mismo 1757, y no dejaba de insinuar alguna advertencias o, si queremos, consejos bibliográficos y de crítica histórica. Los consejos se limitan a 5 reflexiones y una posdata: bibliografía, destino del primer oro procedente de América, el uso de fuentes jurídicas, apología de la colonización hispana (con la figura de Las Casas incluida) y el lenguaje con la ortografía. Y en la posdata aportaba su criterio sobre el origen de la palabra canoa, que se consideraba indio. Llano Zapata tardó 5 meses en responder (lo hizo el 25 de mayo de 1758) después de manifestar su gratitud por los consejos y las palabras de aliento, decidía analizar cada uno de los puntos insinuados por el erudito. Una última carta de don Gregorio, escrita el 24 de junio de 1758, finaliza la correspondencia que he podido localizar 5 .

\section{LOS GRANDES TEMAS DE LA COLONIZACIÓN ESPAÑOLA}

Para mayor claridad expositiva, indicaré en cada punto el criterio inicial de Mayans, la réplica de Llano Zapata y la reflexión última del erudito. Por supuesto, no todos los temas abordados adquieren idéntica importancia, pero permiten comprender la preparación intelectual de ambos corresponsales, así como su criterio básico sobre la historia y los tratadistas de la colonización española de América.

Bibliografía. En dos breves párrafos Mayans aconseja los libros que consideraba fundamentales. En primer lugar la Biblioteca oriental y occidental... de Antonio León Pinelo, recientemente reimpresa por González de Barcia con notables ampliaciones. En segundo lugar, aconsejaba la lectura de la Noticia y juicio de los más principales historiadores del marqués de Mondéjar, que el mismo erudito había publicado. Y finalmente, indicaba una noticia aportada por el P. Juan de Torquemada, en Monarchía Indiana, en que disminuía la originalidad del jesuita José Acosta respecto a su Historia natural y moral de las Indias. He aquí las palabras exactas de Mayans: «Sin olvidar la

\footnotetext{
4. F. Pujol, Respuesta a un amigo y aviso para todos. Dedicada al Ilmo. Sr. Rector y Claustro de la Real y Pontificia Universidad de Santo Domingoo..., con la que se satisface a una duda del Dr. D. Joseph Eusebio Llano Zapata..., Cádiz, imprenta Real de Marina, 1738

5. Las cartas se conservan en el Fondo Mayansiano del Colegio de Corpus Christi de Valencia. Las cartas de Llano Zapata en BAHM, 85, y las de Gregorio Mayans en BAHM, 156,
} 
notable advertencia que dio frai Juan de Torquemada de que el P. Josef de Acosta se apropió la Historia natural i moral de las Indias, no siendo suya.

El historiador peruano expuso su criterio sobre cada uno de los autores aconsejados. Y en primer lugar acerca de León Pinelo. No afirma que posee explícitamente la Biblioteca. «Por lo que toca al primero, que es el señor Pinelo, tengo de él obra sino de tanta consideración, como la que Vmd. me previene, a lo menos más propia para la materia que trato». Y Llano Zapatas explica el título y alcance de la obra, el estado actual del manuscrito y cómo llegó a sus manos. «Es ella el Paraíso en el Nuevo Mundo. Hasta ahora no ha visto la luz pública, a excepción de las primeras frentes y tablas de los capítulos» impresos en Madrid (1656). El manuscrito que poseía Llano es el autógrafo del autor. Escrito en Sevilla, Llano supone que el autor lo enviaría a su hermano, «catedrático de Prima en la Universidad de Lima y ministro togado en su Real Audiencia». De cualquier forma el manuscrito autógrafo (en 2 volúmenes) llegó a sus manos por medio del arzobispo de Charcas, Cayetano Marcellano de Agramont. En efecto, Paraíso en el Nuevo Mundo era inédito y sólo vio la luz pública en el siglo XX.

LlanoZapata confiesa que cita con frecuencia este manuscrito autógrafo de León Pinelo, «en unas partes con elogio, y aun prefiriéndole a los nuestros. En otras con aquella juiciosa crítica, que merece una americano de su mérito». Sin embargo, no deja de confesar que «este sabio hombre se precipitó muchas veces, por querer probar su sistema del Paraíso en el Nuevo Mundo que, no passando los términos de unas conjeturas, se ha quedado en los límites de una nueva paradoxa, bien que fundada, si se contemplan sus razones».Pero, dado que León Pinelo quiso probar su idea, «recogió lo más peregrino de nuestras Indias, se hallan en sus originales bellísimas especies que hacen a mi asumpto». Ante esa amplia exposición de semejante obra, el erudito de Oliva, muy exigente del documento o de la experiencia directa, contestaba: «Tengo por sueño poético el Paraíso del Nuevo Mundo. Supóngolo escrito por ostentación de su amena erudición, tanto peor empleada quanto con mejor ingenio (h)aya escrito. Pero, en fin, el asunto vendrá a ser tan despreciable como la Fénix Troyana del dotor Vicente Marés».

En contraste, la invitación mayansiana a servirse del juicio de Mondéjar sobre los historiadores españoles no parece interesar al peruano, «pues a mi intento no hace mucho». Por lo demás, tampoco intenta estudiar «todos los que han escrito de las Américas», porque constituyen un campo excesivamente amplio. Sí le interesan los autores «que han tratado ya en historias, ya en viages, ya en relaciones, ya en cartas la Historia natural de la América Meridional, que son tantas las mentiras, que ha inventado la malicia y apoya la credulidad, que casi no se puede creer lo mismo que se ve». En consecuencia, el objeto preferente de su estudio es la física, el comercio y las producciones de América del Sur, y, confiesa, siempre será imparcial en sus juicios, aunque no en todos los casos puede certificar la verdad o falsedad de los historiadores.

$\mathrm{Y}$, entre los historiadores que utiliza, que son pocos y de éstos pocos, «algunos que relaxar. Son los mejores, entre los antiguos, Zárate, el señor Pinelo i el Mº. Calancha. Entre los modernos el P. Ovalle, don Pedro Peralta y don Antonio Ulloa». Es decir, junto a Agustín de Zárate, autor de una Historia del descubrimiento y conquista de la 
provincia del Perú (Amberes, 1555) y el Paraíso en el nuevo Mundo de León Pinelo, utiliza la Crónica de S. Agustín del Perú del agustino $\mathrm{M}^{\circ}$. Calancha. Y, en cuanto a los llamados modernos, señala al jesuita Alonso Ovalle, nacido en Chile pero que publicó en Roma su Historia y relación del Reyno de Chile, y de las misiones y ministerios que en él exercita la Compañía de Jesús (1646). Asimismo incluye al peruano Pedro Peralta, rector de fue de la Universidad de San Marcos, y autor de Lima fundada (1732). Finalmente, cita entre los autores consultados a Antonio Ulloa, que junto con Jorge Juan había visitado la zona para medir el grado del meridiano terrestre, y acababa de publicar Relación histórica del viage a la América Meridional (Madrid, 1748). «No todos lo vieron todo», escribe. «Pero juntos hacen un cuerpo de historia más seguro que las que otros hasta aquí han publicado»

Llano confiesa con cierta suficiencia haber «consultado y leído desde mis primeros años» todos estos autores. Más aún, ha «registrado los archivos que ellos vieron y muchos instrumentos que no vieron». Pero en esta búsqueda del pasado histórico peruano precolombino ha consultado los «quipos o annales», que todavía se conservan en templos arruinados o palacios destruidos. Volvemos a encontrar en estricto paralelismo con la actividad de Boturini en Méjico que quiso conocer el pasado precolombino por medio de las pinturas y grabados. Por eso el mismo Zapata repite unas palabras de Mayans, antes citadas, en que comentando la obra de Boturini, lamentaba la ignorancia de los conquistadores que destruyeron esos restos arqueológicos, «de donde nació un daño irreparable en lo tocante a la memorias de las cosas passadas»».

Ahora bien, la breve alusión mayansiana a la crítica de Torquemada al P. Acosta provocó una apasionada apología del jesuita. En principio, Llano Zapato quedó sorprendido por el conocimiento de la novedad del ataque a un autor tan reconocido, buscó la Monarchía Indiana, impresa por González de Barcia y observó que, en efecto, citaba muchas veces al P. Acosta y no para hacerle honor, «como merecían sus tareas literarias», y observa una crítica injusta y que en Torquemada señala más pasión que razón. Entre otras cosas, porque acusa al P. Acosta, tanto cuando habla como cuando calla. En el fondo, Torquemada es crítico sospechoso, porque sólo busca ocasiones para acusar y, donde no las halla, censura su silencio.

Así, después de analizar cinco textos críticos de Torquemada contra Acosta, busca la fuente en que basa la censura de apropiarse la obra. A su juicio, se trata de una «historia duende», que nadie ha visto, y que Acosta utilizó y de la que copió algunos hechos civiles. Y, desde esa perspectiva, Llano Zapata acusa al P. Torquemada. «Y, si para decir que el P. Acosta se apropió la historia, que no era suya, valieran unos fundamentos tan débiles, con mayor razón valdrían otros muy sólidos para decirlo del R. Torquemada». En este caso, se habría apropiado de una Monarchía Indiana, obra del P. Jerónimo Mendieta, a juzgar por los juicios incluidos en el Monologio franciscano $(9$ de mayo), citado por el francés Augustín Betencour, y puede leerse en el Resumen de varones ilustres, y hasta en el prólogo de la edición de Torquemada en 1723.

El peruano intenta escribir con precisión. No se puede confundir la Historia eclesiástica indiana del P. Mendieta con la Monarchía Indiana del P. Torquemada. Pero este último confiesa en repetidas ocasiones que utilizó muchos autores, entre los cuales 
cita al P. Mendieta. Ahora bien, si Torquemada no se puede decir que fuera un «plagiario..., pero no se excusa de la nota de copiante». En su argumentación, todos los historiadores se valen de cuanto dijeron otros autores anteriores y añaden nuevas noticias, como hizo y confiesa Torquemada. Y si a éste «le patrocinan los fueros que a los demás historiadores, con mayor razón favorecerán al P. Acosta, para que pacíficamente goze en la República Literaria la posesión de autor de la Historia natural y moral de las Indias, que hasta ahora nadie se la ha disputado».

Y aunque finaliza su análisis del asunto con una invitación a que Mayans expusiera, si hallaba "pruebas más convincentes», el erudito fue muy prudente es su respuesta. Después de alabar generosamente la persona y obra literaria del P. Acosta, de quien «hago yo singular estimación», no consideraría un «desdoro que pudo disfrutar el trabajo de otro»; y esto no sería difícil de probar «a vista de los manuscritos que se conservan en el Escurial» y de otras noticias conservadas en Simancas. «Quede, pues, el P. Acosta con la estimación que merece, i permítame que no tenga yo por calumnioso el dicho de Torquemada, sino que suspenda el juicio» (24-VI-1758).

El primer oro procedente de América. Entre las observaciones de Mayans aparece un breve apunte sobre el hecho de que el primer oro procedente de las Indias fue utilizado para decorar «la Sala Real de la Aljafería i Palacio Real de Zaragoza». Las diferencias en este punto se centran en el valor de las fuentes de que tanto el erudito como el peruano se valían. Don Gregorio indicaba su fuente, Bartolomé Leonardo de Argensola en los Anales de Aragón. En cambio, su interlocutor señalaba la noticia de un viajero francés del siglo XVII, Baltasar de Monconys que, al hablar de España, decía «que se empleó en la custodia que sirve al Augusto Sacramento de depósito en la santa iglesia de Toledo» (Viajes, París 1645). Llano se inclina por la teoría del viajero francés debido a la devoción de los Reyes Católicos. Por lo demás, el historiador peruano recoge la noticia de que utilizaron el primer oro para construir «un grande relicario» que se conserva en la sacristía de la catedral de Sevilla. De cualquier forma, la intención de Llano Zapata se centra en rechazar la leyenda de que el oro fluía en los ríos de las Indias, mantenida por muchos autores que cita explícitamente.

Los argumentos del historiador peruano no convencieron al buen historiador que era Mayans. El valor de las fuentes no admite dudas, a su criterio. El testimonio de Argensola le parece seguro: «porque el primer dinero con que los Reyes Católicos socorrieron a aquel insigne varón para la empresa del descubrimiento de las Indias se sacó de Aragón, según consta de una libranza del mes de abril del año 1492, que cita a la letra en el lib. 1, cap. 10 de los Anales de Aragón el Dr. Bartolomé Leonardo de Argensola, hombre veraz, i para discutir la creencia de aquel hecho, será necesario provar su imposibilidad, i no la prueba el destino que los Reyes Católicos dieron en parte del primer oro que vino, haciéndole servir a usos sagrados; porque creo que también devió fabricarse moneda, hacerse varias joyas...I assí Vm. me permita que con estimación de sus ingeniosas reflexiones, crea yo este hecho, de que supongo bien informado i fiel relator al aragonés analista, que escribió desfrutando el archivo de aquel Reino»

El P. Las Casas y la leyenda negra. Y a continuación, el centro de la correspondencia: la apología o crítica de la conquista y colonización española y de uno de sus 
protagonistas, el P. Bartolomé de Las Casas. Llano Zapata no pretende entrar en el análisis de la colonización en general, ni en la personalidad de Las Casas. Porque, de hecho, la polémica ha sido constante desde Ginés de Sepúlveda a Menéndez Pidal, Pérez de Tudela, Lewis Hanke, o la apretada síntesis de León Lopetegui, pasando por tantos y tantos apologistas y detractores del obispo de Chiapas. Limitaré mi exposición a los criterios básicos de ambos interlocutores.

El problema aparece formulado con toda claridad por Mayans: «Si la apología, que hace Vm. de los españoles, es de su gobierno, tengo por cierto que no repetirá en ella el error de don Diego de Saavedra que, por no aver visto la primer impresión de letra de tortis de las obras de frai Bartolomé de Las Casas, o Casaus, del año 1552, pensó que eran modernamente fingidas, quizá por averlas tenido a la vista recién impresas con caracteres modernos. Aquel religioso, aunque bueno, tuvo tan indiscreto celo que con él causó la cruelíssima guerra civil que padecieron los Pizarros, como claramente lo dice el inca Garci-Lasso de la Vega. El Consejo de las Indias jurídicamente declaró la inocencia de Hernando Pizarro, según lo advierten D. Fernando Pizarro i Orellana en los Varones ilustres del Nuevo Mundo, i el licenciado Francisco Caro de Torres, en la Historia de las órdenes militares. Bien es menester que Vm. use de buenos colores para hacer que no parezca abominable la ruina que causaron en el Nuevo Mundo los conquistadores españoles, pues las historias no representan en toda la antigüedad otra tan grande».

Ante esta invitación el historiador peruano expone su criterio con amplitud, buen conocimiento de fuentes y bibliografía, y no duda lo más mínimo en censurar a Las Casas, al tiempo que defiende la colonización española, aunque reconoce los abusos cometidos. Como Mayans señalaba que Saavedra Fajardo no creía en la paternidad de Las Casas respecto a sus obras, «y las tenía por modernamente fingidas», lo mismo ocurría en Lima, confiesa Llano, al $\mathrm{M}^{\mathrm{o}}$. Fr. Juan de Meléndez, y a su aprobante Antonio Montalvo, que las tuvieron por supuestas, como se lee en los Tesoros de las Indias: «Ojalá assí fuesen» exclama el peruano indignado.

Llano Zapata conoce un número elevadísimo de ediciones de la obra de Las Casas: 2 en castellano (Sevilla, 1552 y Barcelona, 1642), en francés (París, 1582), en latín (Franfort, 1598) y en italiano (Venecia, 1613). De todas las obras, la más difícil de encontrar es la titulada: Si los reyes, o los príncipes, pueden en conciencia por algún derecho, o en virtud de algún título, enagenar de la corona sus ciudadanos y sus súbditos, y someterlos a la dominación de algún otro señor particular. Esta obra, afirma, escrita en latín, se publicó 2 veces en Alemania y últimamente en Roma (1678). Y, por supuesto, demuestra buen conocimiento de los grandes bibliógrafos: León Pinelo, Nicolás Antonio, Andrés Schott y Du Pin. Por lo demás, el historiador peruano cita otras obras que, bajo pretexto de favorecer a los españoles, acaban ofendiéndolos con dureza. En esa línea, leyó en la librería de san Pablo de Sevilla el Tratado comprobatorio de Imperio soberano y Principado Universal, que los Reyes de Castilla y de León tienen sobre las Indias, impreso en Sevilla por los años 1552, y del que se conserva otro ejemplar en Méjico. El libro fue traducido al latín por Fr. Domingo de la Anunciación Dávila Padilla y aparece citado por el historiador dominico Fr. Jacobo Echard en 
Scriptores ordinis praedicatorum (II, p. 192). Conoce asimismo una Historia General de las Indias, que aprovechó generosamente el cronista Antonio de Herrera.

Después de este preámbulo sobre el conocimiento de fuentes y autores, Llano Zapata emite su juicio sobre Bartolomé de Las Casas: "Los autores que, como el Ilustrísimo Casas, escriben con sangre, dexan a la posteridad más bien libelos que historias. Los escritos de este prelado, donde quiera que tocan, queman. Movió su pluma cierta pasión que más fue zelo indiscreto que charidad reglada. Por defender a unos, calumnió a otros. Fue esto en cierto modo esparcir las semillas de la dissensión el mismo que, por estado y dignidad, estaba obligado a recogerlas. No hallo que esto huviesse sido justicia, ni arte de patrocinar. Hasta hoy con sus escritos renuevan los unos la llaga y avivan otros la ofensa. Siempre que se añadiesse pábulo al incendio de la enemistad, crecerá la llama de la discordia. Esto ha hecho el Ilustrísimo Casas. Esto han causado sus escritos, y esto mismo causarán todos los que no eligiesen un medio entre la piedad y la razón».

A partir de ese planteamiento, el historiador peruano sigue dos líneas expositivas: los críticos de Las Casas en paralelo con los apologistas del obispo de Chiapas. Entre los críticos conoce bien la obra de Ginés de Sepúlveda, pero no le gusta, y lo expone con claridad: «No entra en este número (quienes se opusieron al obispo de Chiapas) el doctor Sepúlveda. Fue temeraria, poco cristiana y publicó en Roma», huyendo de la prohibición de Carlos V. En cambio, entre los opositores de Las Casas señala al cardenal García de Loaisa, Presidente del Consejo de Indias, a Sebastián Ramírez obispo de Cuenca y a Juan Zares obispo de Lugo. Parece, dice, que, como si previendo el futuro, señalaron las funestas consecuencias que sobrevendrían sobre España y sobre la evangelización de los indios. «Pero prevaleció la importunidad de su autor. De aquí vino todo el descrédito que injustamente padece y padecerá nuestra nación en las plumas de los extranjeros, como se quexan los señores Sandoval, obispo de Pamplona, y Pizarro, Consejero de Castilla».

Decíamos antes -y resulta evidente- que Las Casas ha sido siempre, y desde el primer momento, un personaje controvertido. Y Llano lo sabía. Así señala la visión favorable del prelado por parte de Fr. Juan Remesal, en la Historia de Chiapas, «a quien probablemente copian las plumas extranjeras para exaltarle sus virtudes». En contraste el licenciado Bartolomé de Albornoz en Cartill. De contrat. (Arte de los contratos, 1573), casi coetáneo de Las Casas y que residió muchos años en América de Norte, asegura que el obispo de Chiapas, «no vio, ni experimentó los sangrientos estragos que nos imputa este prelado de aquellas conquistas».

El historiador peruano pretende demostrar el descrédito que han hecho los extranjeros de la colonización española, basados en la obra de Las Casas. Así lo explica con pasión: «Raro será el viajero, historiador, diarista o colector de noticia, donde no se encuentren dicterios, oprobios y blasfemias contra nuestros trabajos, desvelos y fatigas en la conversión, enseñanza y reducción de los indios. Rarísimo será el crítico, tunante, poeta o decidor, que no quiera con descrédito de nuestro zelo acreditar la infelicidad y pobreza de su pluma, introduciendo en tragedias, novelas y comedias muchas ficciones, patrañas y quimeras, que sólo han existido en los países imaginarios del enco- 
no, envidia y rabia, con que ven nuestros progressos y adelantamientos en las Indias. Puedo asegurar a Vmd. que he leído con cuidado algunos autores extranjeros (debía decirle que muchos, y aun muchísimos) y no llegan a tres los que exceptúo de estas imposturas». Y, en esa línea, después de señalar, entre los que exceptúa de las imposturas, al dominico Labat y al jesuita Charlevoix, aprovecha los testimonios de estos religiosos extranjeros para exponer su idea. «Estos religiosos afirman que los ingleses y holandeses executaron de propósito muchas atrocidades en las Indias con el ánimo de cargarlas a los nuestros, para hacernos espantosos a los indios»

Llano Zapata sabe bien que ese criterio favorable a Las Casas tan general entre los extranjeros asimismo se extendió entre muchos españoles. «Pero como los caprichos de algunos autores passan a contagio, no han faltado plumas españolas en nuestros días, que con no menos espantosas declamaciones han hecho revivir la imprudencia de este prelado, no sólo con pasajes y citas que nos afrentan, sino componiendo en castellano y en latín libros enteros en que han transferido a sus plumas el mismo zelo del señor Casas, llamándole unos mártir de la verdad, y apellidándole otros redemptor de los indios contra la tiranía de los españoles, y no faltando quien assegure que escribió sus obras inspirado de Dios». Y esta fiebre alcanza también a religiosos de prestigio. En esa línea señala el juicio de P. Echard, dominico galo que, suponiendo a Las Casas originario de Francia, escribe hablando de su conversión. «Divino repente afflatu numine, mutatis consiliis, indorum saluti et libertati deinceps incumbere proposuit». Sin embargo, el mismo peruano se aprovecha de las palabras de Echard en el sentido de que sus palabras críticas sobre la colonización no demuestran que los españoles fueran unos monstruos, porque «apud quas enim nationes non similia eruperunt hominum portenta». ¿Pues en qué naciones no se cometieron semejantes barbaridades?

Por lo demás, el historiador peruano también reconoce que algunos extranjeros confiesan la labor colonizadora y apostólica española. Son pocos, pero existen y no duda en expresar su nombre y sus obras, como vimos, al dominico Labat y al jesuita Charlevoix. La raíz de esa crítica tan generalizada viene basada en gran parte, a su juicio, por la conversión de los indios a la fe católica. Y para demostrar su aserto, se vale de dos textos. Uno del misionero español Joseph Gumilla en su Orinoco ilustrado ${ }^{6}$. El segundo texto está tomado del jesuita bohemo que, en carta al P. Prepósito de la Compañía, escribía: «Aquí ha passado el Reyno de Dios que su justicia, por un juicio formidable, ha quitado a estas grandes provincias de la Europa, que se han abandonado al espíritu del cisma y la herejía». Y el mismo Llano confirma este juicio por su experiencia personal: «Puedo subscribir a este autor, afirmando que apenas se hallará en nuestras poblaciones indio que no sea christiano y muy buen christiano, a excepción de uno que otro que conserva los defectos nacionales, no están de esto libres las naciones más cultas». Sin embargo, Llano Zapata no alude a las diferencias surgidas

\footnotetext{
6. Llano Zapata transcribe las palabras del P. Gumilla: «Gran pena me da el veer que los libros en que se habla mal de la fee de los indios, (vol. en 4, edición parisiense de 1750), deduciendo quatro argumentos que convencen con razón y autoridad» corran por tantas manos, y que no haya ojos para leer los que con tanta evidencia prueban lo contrario».
} 
en el mismo Perú sobre los métodos empleados por los misioneros, la actitud de los obispos y de los doctrineros. Esas diferencias explican la campaña de «extinción de las idolatrías», en una etapa del siglo XVII, con una afán inquisitorial y de control de la sociedad india. Aspecto éste que ha merecido recientes estudios (García Cabrera, G. Ramos, H. Urbano, P. Duviols...)

De cualquier forma, el historiador peruano intenta demostrar los errores de Las Casas y la imposibilidad del dominico para constatar la serie de afirmaciones, exageradas e injustas, que escribió en sus obras. Y lo que es peor, dice falsedades y mentiras. De hecho, la intención final de Llano Zapata era descalificar la persona y obra del obispo de Chiapas.

Afirmación tajante: Las Casas dice falsedades. Y, por supuesto, respecto al número de indios que sucumbieron como consecuencia de los abusos de los españoles: «Y aunque el señor Casas nos da millares de indios consumados al rigor de las conquistas y malos tratamientos de los nuestros, fue ésta una aritmética de caprichos; que, bien examinada, rebasándole los ceros, nos queda en dezenas, y si se ven con ojos críticos, ni aun en unidades. No fueron tantos los millones de indios que poblaban aquellos países, como juiciosamente reflexiona Mr. Bufón (tomo 3, página 311 y 312, Historia natural... con razón y autoridad» (p. 21). Conviene tener en cuenta tanto la acusación de falsedad, como una de las razones utilizadas para negar la principal crítica de Las Casas: la obra de Bufón que disminuía el número de indios americanos en el siglo XVI. Esta disminución de indios lo fundamenta el historiador peruano en el criterio del naturalista francés. Pero no deja de constituir un hecho curioso que también los estudios demográficos recientes demuestran que el número de los indios en el siglo XVI era menor que los supuestos por Las Casas?

Un segundo argumento utilizado por Llano para disminuir la credibilidad del obispo de Chiapas es la imposibilidad de que visitara las zonas de América de las que habla. «Además, que este prelado no viajó todas nuestras Indias, ni vio los progressos de tan dilatadas conquistas. Sólo residió en aquellos primeros tiempos en las Islas Lucayas donde, siendo asesor de Diego Velázquez, gobernador de Cuba, se ordenó a título de cura de Zaguarama. Después, hecho religioso dominico, admitió el obispado de Chiapas, que gobernó poco más de ocho años». Y si bien corrige al Inca Garcilaso de la Vega que negó su residencia en Chiapas, confiesa que residió muy poco tiempo en su obispado para trasladarse después a España, y asegura que «este prelado no viajó todas nuestras Indias, ni vio los progressos de tan dilatadas conquistas». Esta tajante afirmación de Llano Zapata aparece confirmada por el testimonio del licenciado Bartolomé de Albornoz, que «casi coetáneo del señor Casas, y residió muchos años en la América Septentrional, donde asegura con otros autores, que cita, que (Casas) no vio, ni experimentó los sangrientos estragos que nos imputa este prelado en aquellas conquistas».

7. V. PÉREZ MoredA, «La población de España y las Indias en los siglos XVI y XVII», en Boletín de la Real Academia de la Historia, CCVII (2010), pp. 513-533. 
Más aún, sigue el historiador peruano, no pueden utilizarse los restos humanos hallados en amplias fosas llenas de cadáveres para condenar a los españoles como causantes de esas mortandades. Una razón potísima: «¿Dónde, pues, están estas Indias arruinadas? ¿Dónde estos montones de cadáveres? ¿Dónde estos reynos destruidos?. Están, desde luego en las supuestas relaciones del señor Casas que quizá, y si quizá, causaron entre los nuestros mayores estragos que los que nos acusa cometidos con los indios» Llano justifica su criterio en los historiadores, como el Inca Garcilaso y el Gómara. Y añade: «Y mucho más diremos los que hemos nacido en aquellos países, viajado y visto progressos muy distintos a todo lo que en sus sangrientas relaciones figura y representa este prelado que (aunque en otras cosas sería muy bueno) se dexó llevar en esto de más que ciega y vana preocupación».

Viene esta defensa a contradecir las afirmaciones de los críticos de la colonización española en el sentido de que la mortandad producida por los españoles se demostraba en los numerosos cadáveres encontrados en sepulturas. Las palabras de Llano Zapata son tajantes: «Y, si por la multitud de cadáveres que se encuentran en nuestras Indias se quieren sacar aquellos estragos, muy poco sabe de historia quien assí lo juzga. El mayor osario, que se vee en las dos Américas, es el de Quipay-Pan. Éste no lo cuasaron los españoles. Los mismos indios motivaron aquella ruina. Con la sangrienta batalla que se dieron Ata-Hualpa y Huascar, quedaron en el campo muertos más de 300 mil indios. Hasta hoy sus despojos son en el Perú espantoso objeto de horror. Como assí mismo los 20 mil que poco antes Guayna-Capac havía mandado abismar en la laguna de Carangue, que desde entonces tomó el nombre de Yahuar-Cocha, que significa lago de Sangre».

La historiografía reciente parece dar la razón a Llano Zapata. Los historiadores modernos disminuyen el número de habitantes anteriores al descubrimiento; y sin negar la mortandad inicial en La Española (la fiebre del oro, y, por supuesto, viruela, sarampión, tifus, gripe, peste tos ferina, en palabras de Pérez Moreda), la disminución demográfica en el Imperio Inca tuvo su origen en las guerras civiles entre los mismos incas (Huascar Cápac y Atahualpa, los hijos de Huayna Cápac), agravada por las grandes epidemias de 1546, 1558 y 1585-91 ${ }^{8}$. En cambio, según el mismo Pérez Moreda, la adaptación de los indios a la minería de la plata más bien pudo producir un aumento económico y demográfico en el Imperio Inca.

Desde esa perspectiva Llano Zapata revuelve el argumento: más atrocidades cometieron los indios sobre los españoles. Esta sorprendente afirmación intenta demostrarla con hechos históricos pasados y con su experiencia personal vivida. «¿Quántas atrocidades (imponderablemente mayores) han hecho, y hacen hasta hoy los indios con los españoles? Muy buen testigo soy yo, y lo son todos los que hoy viven en el Perú, Chile y Buenos Ayres». Y el historiador peruano recuerda el sangriento espectáculo producido por los indios pampas contra los españoles, apenas cinco años antes. O la «reciente historia en las montañas de Tarma y Cerro de la Sal, donde perecieron en Quimiri las

8. PÉrez MoredA, p. 530. 
tropas españolas con aquel valeroso capitán D. Fabricio Bartholí»», o la tragedia de Coarochiry, «donde los nuestros fueron sangrientas víctimas del furor de los indios». Todos estos hechos, bien conocidos por el historiador peruano, le llevan a una conclusión: "Y si el señor Casas ha llenado el mundo de horror y espanto con su Destrucción de los indios por los españoles, mayor espanto y horror pondría a las gentes el que, zeloso por la honra de nuestra nación, se instituyesse escribir Destrucción de los espanoles por los indios. Entonces vería el mundo quiénes han derramado más sangre, si los españoles o los indios». Llano Zapata no tiene dudas: los españoles desde hace doscientos años no derraman sangre de los indios, y si alguna vez cogen las armas, es para defender «la religión, el rey y la patria».

\section{JUSTIFICACIÓN DE LA POLÍTICA DE LA MONARQUÍA}

No hay duda de que los españoles cometieron abusos en la conquista y colonización de América, a juicio del peruano, pero no deben ocultar los méritos. Y, sobre todo deben vindicarse los méritos ante las exageradas acusaciones de Las Casas. «Los excesos que los nuestros cometieron en las Indias no se extendieron a provincias, ni a pueblos, ni aun a familias. Se contuvieron a unos particulares, a quienes los primeros, por ignorancia o preocupación, sacrificaron a sus intereses y frívolos recelos. No es esto excusar, ni defender, sus atentados casi indispensables en aquella ocurrencia y confusión de negocios. Es sí vindicarnos de la pluma del señor Casas que, sin prevenir las consequencias de sus destempladas relaciones, y más que ponderados gritos, quiso hacer transcendental una culpa que sólo contaminó a unos pocos de los nuestros; y en el mismo principio se extirpó de raíz, no haviendo quedado ni aun la menor reliquia de aquel contagio»..

Y, por supuesto, los abusos fueron duramente castigados como intenta demostrar, tanto por las leyes, como por la actitud de los reyes. Así Llano Zapata aporta testimonios directos de los monarcas, como el respeto con que Felipe II se dirige siempre a D. Baltasar Poma Huavaca, tío del emperador Huáscar, tratándole siempre de a vos señor D. Baltasar... Lo mismo Felipe IV que, después de escribir a la Audiencia de Méjico, encargando el cuidado de los indios y el desagravio a sus quejas, «añadió de su puño: Quiero me deis satisfacción a mí, y al mundo, del modo de tratar essos mis vasallos; $y$ de no hacerlo, y de que en respuesta no vea yo executados exemplares castigos en los que huvieren excedido en esta parte, me daré por deservido. Y assegúroos que, aunque no lo remedieis, lo tengo de remediar y mandaros hacer gran cargo de las más leves omisiones en esto, por ser contra Dios y contra mí, y en total destruición de estos Reynos, cuyos naturales estimo y quiero sean tratados como lo merecen vasallos que tanto la han engrandecido e ilustrado».

Asimismo, repite textos de la legislación española y documentos aportados por historiadores como Valenzuela y Solórzano. Insiste, por supuesto, en el hecho de que, según la legislación española, se tenían por delitos públicos las ofensas hechas a los indios. Como prueba utiliza los testimonios legales citados por Solórzano, en la Política Indiana, lib. 1, cap. 22, pág. 44: «En la ley XXI, tit. 10, lib. 6 de la Recopilación se 
manda que sean castigados con mayor rigor los españoles que injuriaran o ofendieren a los indios, que si los mismos delitos se cometiesen contra españoles, y se declaran por delitos públicos».

En consecuencia, el historiador peruano se extiende en señalar las gracias y privilegios sociales y económicos concedidos por los monarcas españoles: muy cortos tributos respecto a la riqueza de las tierras, se les reparten tierras, «son libres de derechos y gavelas la maderas de los montes, las salinas, las pescas de todo linaje de marinos, todos los frutos que produce la tierra y las minas (esto es, descubrirlas, buscarlas y trabajarlas) sino es entre los indios».Y, por supuesto, se ha respetado la nobleza de sus antiguos caciques. Por lo demás, cuántos esfuerzos han costado a los españoles la administración política, la enseñanza y las misiones apostólicas. Sin olvidar, por supuesto, las gracias eclesiásticas concedidas a los indios; pues, exceptuados el ayuno y abstinencia, se les ha dispensado «generalmente para siempre el casamiento con las más consanguíneas, y sujetando al párroco particular o vicario de cada pueblo los delitos de herejía, superstición o judaísmo».

Llano no deja de recordar el aspecto honorífico concedido por los monarcas a los descendientes de la nobleza azteca e inca. Juan Hernández estudia la evolución de un mayorazgo creado en torno a los descendientes de Moctezuma9. Y el mismo Mayans se sentía orgulloso de la posibilidad de enlace matrimonial de una de sus hijas con uno de los descendientes de la familia imperial peruana. Sólo la actitud de los gobernantes españoles -como se deduce de la correspondencia del erudito con el ministro Manuel de Roda- impidió el matrimonio ${ }^{10}$.

No es menester mucho esfuerzo para deducir el juicio definitivo de Llano Zapata sobre la persona y actitud de Bartolomé de Las Casas. Así, después de citar la ley XXI, tit. 10, lib. 6 de la Recopilación, antes citada, en que se manda castigar con mayor dureza a los españoles que maltratan a los indios, que a éstos si ofenden a los españoles, escribe: «Esto quisiera yo que leyeran todos los que nos calumnian. No sé con qué cara entonces citarían al señor Casas, que más bien dio a conocer en sus obras la indolencia de su genio, que manifestó un pequeño rasgo de su zelo verdadero. Le predominó la pasión, y se aventuró a todo el riesgo que corren los que no llevan por guía el Non sunt facienda bona, unde veniant mala. Por esso, dexando los bueno de ser bueno, quando de ello proviene mal, no lo son las obras del señor Casas que, baxo la máscara de piedad, religión y zelo, nos han producido tantos males, quantos son y serán las plumas maldicientes que, sin distinción de tiempos, se abroquelan de sus supuestas relaciones para llenarnos de dicterios, oprobios, infamias y blasfemias.

La respuesta de Mayans resulta coherente con sus primeros juicios. «No sea pródigo del tiempo, de que necesita para su grande obra. Con menos trabajo suyo quedaría

\footnotetext{
9. J. HERnÁNDEZ FrAnCO, «El mayorazgo Moctezuma: reflexiones sobre un proceso de movilidad vertical con alternancias (1509-1807)», en Estudis. Revista de Historia Moderna, n. 32 (2006), pp. 215-236.

10. Puede seguirse el proceso, además de la correspondencia con Ucho-Inca, en G. MAYANS Y SISCAR, Epistolario X. Mayans con Manuel de Roda y el conde de Aranda, transcripción, estudio preliminar y notas de A. Mestre Sanchis, Valencia, Ayuntamiento de Oliva, 1990.
} 
yo suficientemente instruido, i más aviendo sido siempre de su sentir, especialmente en lo que toca al obispo don Fr. Bartolomé de las Casas, o Casaus, que ciertamente fue indiscretamente celoso i causador de gravísimos daños»..

Finalmente hay varios aspectos de menor profundidad polémica, pero no menos curiosos. Como Mayans había acusado a Las Casas de haber influido en la guerra que sufrieron los Pizarros y la declaración de inocencia de Hernando Pizarro, el historiador peruano hace un alarde de conocimientos bibliográficos. En el fondo, defiende la inocencia de Hernando Pizarro, pero acusa con contundencia de traidor a su hermano Gonzalo, dando prueba desde la sentencia dictada por el imparcial Pedro de Gasca (a quien elogia con entusiasmo) hasta los testimonios conservados en lápidas en sus mismos días, como refiere Antonio Ulloa, en su Relación histórica del viage a la América Meridional, que había aparecido en Madrid en 1748.

\section{ASPECTOS GRAMATICALES Y ORTOGRÁFICOS}

Resulta curiosa la alusión a temas concretos propios del momento. La ortografía, que impuesta por la Real Academia de la Lengua, continuaba siendo polémica, y concretamente nunca fue aceptada por Mayans. Llano se declara observante fiel de las normas de la Academia, salvo en casos, evidentes a su criterio, como el caso de Meri-Dional, con guión interpuesto. Por lo demás, acepta la demostración hecha por don Gregorio, de que la palabra canoa no tiene origen indio, pues había sido utilizada por Nebrija en su Vocabulario español i latino, impreso en 1492, antes del regreso de Colón. Esa demostración mayansiana, aceptada por el peruano, sirvió para que Llano Zapata hiciera una exhibición de sus conocimientos filológicos, nada despreciables: la palabra canoa existía en italiano, francés, latín, griego y aun tenía raíces hebreas.

Dos proyectos, insinuados por Llano Zapata encontraron el aliento del erudito de Oliva. La redacción de una Biblioteca Americana serviría para permitir el conocimiento de la actividad literaria y científica desarrollada en las Indias. Y una colección de obras poéticas latinas y quechuas. «I ojalá que, assí como vienen los metales preciosos de aquellos países, vinieran también las obras de los ingenios que los ennoblecen»

En dos cosas discrepaba Mayans. El erudito no podía aceptar la invitación de Llano a que indicara esa noticia de Nebrija sobre la palabra canoa a la Real Academia de la Lengua. No estaba en disposición de establecer críticas, ni observaciones eruditas, a la Real Institución, después de las divergencias ya conocidas. Y, en segundo lugar, el deseo del peruano de trasladarse a Valencia para tener una más intensa relación cultural con el erudito de Oliva. No se le ocurra, dice don Gregorio. En Valencia no encontraría ni ambiente intelectual, ni fuentes documentales. El mismo don Gregorio dirá con claridad: «Mis estudios han sido otros mui diversos, en los quales a nadie me niego. En essos de Vm. deseo ser discípulo». Vaya a Madrid, donde podrá consultar las fuentes originales, tanto en El Escorial, como en la Real Biblioteca. Y, por supuesto, no comunique a nadie sus proyectos, pues los envidiosos procurarán impedir su desarrollo. Era su idea, fruto de su experiencia personal: muchos prometen realizar los proyectos, para 
que no se lleven a cabo. Así finaliza una breve, pero intensa y curiosa correspondencia entre dos historiadores a mediados del siglo XVIII

\section{ACOTACIÓN FINAL}

La colonización española de América fue un tema constante en la dialéctica apología-crítica, y que también abarcó todo nuestro siglo XVIII. Feijoo en Glorias de España defendió con calor la actividad apostólica y civilizadora de misioneros y colonizadores. Hubo abusos, pero también los cometieron -y mayores- otros países, que no han recibido tantas críticas. La razón, a su juicio, radica en que los abusos de esos países eran desconocidos porque no recibieron críticas para su corrección. Pero en cualquier circunstancia surgía el temor a las críticas.

Baste ver la reacción en la Corte con motivo de la publicación de Idea de una historia general de las Indias de Boturini (1746). Al margen de la cerrada actitud de Nasarre que pretendía ver el peligro doctrinal de las teorías de Vico, o el desprecio desde el aspecto científico de un newtoniano como Jorge Juan, las palabras del bibliotecario real Martínez Pingarrón expresan la suspicacia generalizada. Comunica las polémicas y divergencias interpretativas. Y, después de indicar la importancia de Principios de una ciencia nueva de Vico, como punto de referencia en la base ideológica de Boturini, añadía. «Me falta el tiempo, pero iré diciendo por correos los autores de que se puede aver valido, echándolos a perder para desacreditar a nuestra nación» ${ }^{11}$

Boturini murió en 1755, incomprendido y censurado. En esas circunstancias presentó Llano Zapata su proyecto al bailío Julián Arriaga, Secretario de Estado de Indias que, según el historiador peruano, protegía la empresa. Y las Memorias histórico-physico-críticas de la América Meri-dional pretendían ser una apología de la colonización española y rebatir los argumentos contrarios tradicionales.

He limitado mi exposición a esclarecer el intercambio de criterios entre Mayans y el historiador peruano sobre la colonización española de las Indias. En ningún momento he pretendido conocer la reacción gubernamental ante el afán apologético de las Memorias. En cualquier caso, resulta evidente que el gobierno de Ricardo Wall, con un Secretario de Estado de Indias como Julián Arriaga, no pudo (muerte de la reina y enfermedad de Fernando VI) o no quiso (en polémica con jesuitas y colegiales) explotar el espíritu apologético. La escasez de ejemplares en las bibliotecas españolas así parece demostrarlo.

Aunque, de hecho, las mayores críticas contra la historia cultura española y, por supuesto, contra la conquista y colonización de las Indias fue posterior. Y la apología de Llano Zapata estaba lejos de responder a las críticas de historiadores como Robertson y, sobre todo, de los furibundos ataques de los philosophes desde Masson de Morvilliers al abate Raynal. La defensa ante esas nuevas críticas darían pie a la serie

11. Martínez Pingarrón a Mayans, 16-VII-1746, en G. MAYAnS SISCAR, Epistolario VII. Mayans y Martínez Pingarrón. Historia cultural de la Real Biblioteca, Transcripción, estudio preliminar y notas de A. Mestre Sanchis, Valencia, Ayuntamiento de Oliva, 1987. 
de apologías de España, propiciadas por Floridablanca y simbolizadas por Forner. Esa apología también abarcaba el campo concreto de la colonización de América. Fue el momento de la creación del Archivo de Indias llevada a cabo por Juan Bautista Muñoz. 